
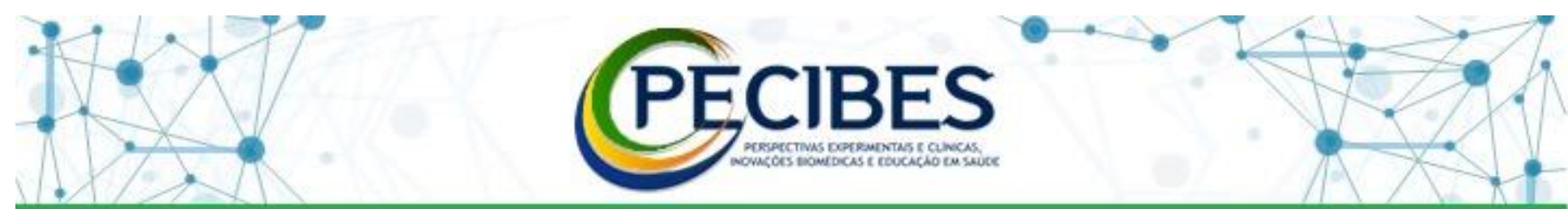

\title{
RESUMO
}

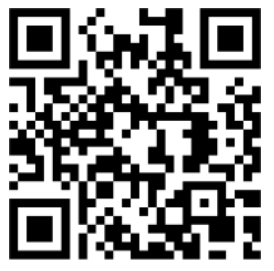

http://www.seer.ufms.br/index.p $\mathrm{hp} /$ pecibes/index

\begin{abstract}
*Autor Alex Yuiti Ogura,

Universidade Federal de Mato Grosso do Sul UFMS. E-mail: alex.yuiti.ogura@gmail.co $\mathrm{m}$
\end{abstract}

Descritores:

Descriptores: Frecuencía Cardíaca. Indicadores de Salud. Adolescente. Ninõ.

Key words: Heart Rate. Health Status Indicators. Adolescent. Children.

\section{Análise da associação entre frequência cardíaca e indicadores de treinamento físico em jovens praticantes de futebol}

Analysis of association between heart rate and exercise training practice in young soccer players

Alex Yuiti Ogura ${ }^{1}$, Tayla Campagna de Assis ${ }^{2}$, Marianna Rabelo de Carvalho, Yann ${ }^{3}$ Zurutuza $^{4}$, Paula Felippe Martinez ${ }^{5}$, Silvio Assis de Oliveira-Junior ${ }^{6}$.

1.Aluno de graduação, Curso de Fisioterapia, Instituto Integrado de Saúde (INISA), Universidade Federal de Mato Grosso do Sul (UFMS)

2.Profissional de Educação Física, Doutoranda no Programa de Pós-Graduação em Saúde e Desenvolvimento na Região Centro-Oeste (PPGSD), Faculdade de Medicina (FAMED), Universidade Federal de Mato Grosso do Sul (UFMS)

3.Fisioterapeuta, Doutoranda no Programa de Pós-Graduação em Saúde e Desenvolvimento na Região Centro-Oeste (PPGSD), Faculdade de Medicina (FAMED), Universidade Federal de Mato Grosso do Sul (UFMS)

4.Fisioterapeuta, Mestrando no Programa de Pós-Graduação em Ciências do Movimento (PPGCMov), Instituto Integrado de Saúde (INISA), Universidade Federal de Mato Grosso do Sul (UFMS)

5.Fisioterapeuta, Doutora em Fisiopatologia em Clínica Médica, Docente do Instituto Integrado de Saúde (INISA), Universidade Federal de Mato Grosso do Sul (UFMS)

6.Fisioterapeuta, Doutor em Fisiopatologia em Clínica Médica, Docente do Instituto Integrado de Saúde (INISA), Universidade Federal de Mato Grosso do Sul (UFMS)

Introdução: Características socioculturais, meios de comunicação, ambiente familiar e social, além defatores internos, que são os definidos pelos indicadores de saúde, podem afetar diretamente o ciclo de vida de jovens esportistas. Nesse contexto, incluem-se frequência cardíaca (FC) de repouso e exposição a demandas físico-motoras advindas da prática sistemática de treinamento competitivo. Objetivo: Analisar a associação entre FC de repouso e indicadores de prática de treinamento físico em crianças e adolescentes praticantes de futebol. Casuística e Métodos: A casuística integrou 27 participantes com idades entre 10 a 17 anos (23 meninos e 4 meninas), procedentes Projeto Escola Pública de Futebol, pólo José Abraão, de Campo Grande, MS. Para avaliação da FC, foi utilizado um cardiofrequencímetro (Polar Electro, modelo V800). A coleta foi feita em ambiente fechado com luz e temperatura controladas e a FC foi aferida no período de 10 minutos com o participante em repouso em decúbito dorsal. A exposição foi registrada a partir de dados de histórico (HT) e carga horária semanal (CHSem)de treinamento. Para análise dos resultados, foi utilizada Correlação Linear de Pearson, sob nível de significância de 5\%. Projeto foi aprovado pelo cômite de Ética e Pesquisa com Seres Humanos (CEP/UFMS), O presente estudo foi aprovado pelo Comitê de Ética em Pesquisa (CEP/ UFMS), sob CAAE 79974317.4.0000.0021. Resultados: Foi observada correlação inversamente proporcional e moderada entre os valores de FC e CHSem $(r=-0,583 ; p=0,001)$. Achados similares foram obtidos na associação entre HT e FC $(r=-0,440 ; p=0,022)$. Não foram observadas correlações significativas entre HT e CHSem (p>0,050). Conclusão: Maiores níveis de exposição ao esforço físico se associam com menores medidas de FC de repouso em jovens atletas, o que pode indicar maior condicionamento físico em resposta à prática sistemática de treinamento físico esportivo. Apoio: UFMS, CAPES (Cód. 001), FUNDECT, CNPq. 